\title{
DIFERENCIAÇÃO E FOCO PARA OBTENÇÃO DE VANTAGEM COMPETITIVA: O CASO DA BETA SISTEMAS
}

\author{
Roberta Rodrigues Faoro \\ rbrodrig@ucs.br \\ Universidade de Caxias do Sul - Caxias do Sul, RS / Brasil \\ Pelayo Munhoz Olea \\ pelayo.olea@gmail.com \\ Universidade de Caxias do Sul - Caxias do Sul, RS / Brasil
}

Sylvia Maria Azevedo Roesch

sylviaroesch@gmail.com

Universidade de Caxias do Sul - Caxias do Sul, RS / Brasil

Marcelo Faoro de Abreu

marcelo.faoro@ucs.br

Universidade de Caxias do Sul - Caxias do Sul, RS / Brasil

http://dx.doi.org/10.1590/1413-2311.0322013.43244

Recebido em 23/07/2013

Aprovado em 28/05/2014

Disponibilizado em 01/12/2014

Avaliado pelo sistema double blind review

Revista Eletrônica de Administração

Editor: Luís Felipe Nascimento

ISSN 1413-2311 (versão on-line)

Editada pela Escola de Administração da Universidade Federal do Rio Grande do Sul.

Periodicidade: Quadrimestral

Sistema requerido: Adobe Acrobat Reader.

\section{RESUMO}

Este caso expõe elementos para reflexões e discussões sobre posicionamentos estratégicos em uma empresa de desenvolvimento de softwares e consultoria em tecnologia da informação. Com sede na Serra Gaúcha, a empresa atua em todo o território nacional, sendo que os seus principais clientes estão localizados nos estados do Rio Grande do Sul, Santa Catarina, São Paulo, Bahia e Mato Grosso do Sul. O caso se desdobra a partir da volta de uma viagem do jovem proprietário da empresa de desenvolvimento de softwares e consultoria em tecnologia da informação à Salvador, onde o mesmo fechou mais um grande projeto com um dos seus melhores clientes do setor de fruticultura, mas ao invés de estar contente estava muito preocupado sobre como iria entregar o projeto no prazo acordado entre as partes, em virtude de sua equipe estar sobrecarregada de trabalho. Afinal, atendendo clientes de mais de trinta ramos de atividades a empresa enfrenta um dilema estratégico: especializar-se ou pulverizar sua atuação em diversos setores? Portanto, qual estratégia a empresa deveria escolher? Os dados para a elaboração deste caso de ensino foram obtidos através de entrevistas 
Roberta Rodrigues Faoro, Pelayo Munhoz Olea, Sylvia Maria Azevedo Roesch \& Marcelo Faoro de Abreu

semiestruturadas com os gestores e por meio de dados secundários como documentos internos, sites e observação direta. Este caso pode ser utilizado como ferramenta auxiliar de ensino, principalmente em disciplinas relacionadas à estratégia, na graduação e pós-graduação lato sensu do curso de administração.

Palavras-Chave: Estratégia; Posicionamento; Foco; Especialização.

\title{
DIFFERENTIATION AND FOCUS TO GAIN COMPETITIVE ADVANTAGE: THE CASE OF BETA SYSTEMS
}

\begin{abstract}
This case exposes elements for reflections and discussions about strategic positioning in an enterprise software development and consulting in information technology. Based in Serra Gaucha, the company operates throughout the national territory, with its main customers are located in the states of Rio Grande do Sul, Santa Catarina, Sao Paulo, Bahia and Mato Grosso do Sul. The case unfolds from the back of a journey of the young owner of the company software development and consulting in information technology to Salvador, where it shut another big project with one of its best customers in the industry of fruit, but instead of being content was very worried about how he would deliver the project within agreed between the parties, by virtue of its staff being overworked. After all, serving customers in more than thirty areas of activity the company faces a strategic dilemma: to specialize or spray your performance in various sectors? So what strategy should the firm choose? The data for the preparation of this teaching case were obtained through semi-structured interviews with managers and through secondary data such as internal documents, websites, and direct observation. This case can be used as an auxiliary tool for teaching, especially in disciplines related to strategy, undergraduate and post-graduation management courses.
\end{abstract}

Keywords: Strategy; Positioning; Focus; Expertise.

\section{DIFERENCIACIÓN Y ENFOQUE A OBTENCIÓN DE VENTAJA COMPETITIVA: EL CASO DE BETA SYSTEMS}

\section{RESUMEN}

Este caso expone elementos para reflexiones y discusiones sobre el posicionamiento estratégico en un desarrollo de software empresarial y consultoría en tecnologías de la información. Con sede en Serra Gaucha, la compañía opera en todo el territorio nacional, y sus principales clientes se encuentran en los estados de Rio Grande do Sul, Santa Catarina, Sao Paulo, Bahía y Mato Grosso do Sul. El caso se desarrolla a partir de un viaje por el joven propietario de la empresa de desarrollo de software y consultoría en tecnologías de la información a Salvador, donde cerró otro gran proyecto con uno de sus mejores clientes de la industria frutícola, pero la en lugar de ser el contenido estaba muy preocupado por cómo iba a entregar el proyecto en el plazo acordado entre las partes, en virtud de su personal de exceso de trabajo. Después de todo, que atienden a clientes en más de treinta áreas de actividad de la

REAd | Porto Alegre - Edição 79 - N 3 - setembro/dezembro 2014 - p. 838-856 
empresa se enfrenta a un dilema estratégico: a especializarse o pulverizar su actuación en diversos sectores? Entonces, ¿qué estrategia debe elegir la empresa? Los datos para la elaboración de este caso de enseñanza se obtuvieron a través de entrevistas semi-estructuradas con los administradores ya través de datos secundarios como documentos internos, sitios web, y la observación directa. Este caso puede ser utilizado como una herramienta de enseñanza auxiliar, especialmente en disciplinas relacionadas con la estrategia de la graduación y cursos de post-graduación en el curso de la administración.

Palabras clave: Estrategia; posicionamiento; Enfoque; Especialización.

\section{INTRODUÇÃO}

Era outubro de 2009 quando, em um voo entre Salvador e Porto Alegre, Roberto, um jovem empresário, proprietário da Beta Sistemas, pensava sobre como cumpriria o contrato que há poucas horas havia assinado com um de seus principais clientes na Capital Baiana. O que mais incomodava Roberto não eram as questões técnicas inerentes ao projeto contratado e sim o volume de trabalho e o tempo limitado para a entrega de um novo software para a gestão da distribuição de frutas no atacado.

Roberto questionava-se sobre a necessidade de assinar aquele contrato, mas não via outra possibilidade se não assumir o desafio, uma vez que se tratava de um projeto estratégico para a Beta por se tratar de um setor onde está concentrado quase $60 \%$ do faturamento da empresa. Portanto, a não aceitação implicaria na possível perda, não só do cliente, mas também da condição de principal fornecedor de softwares para aquele setor econômico.

O empresário procurava, durante aquela viagem, encontrar os motivos que levaram sua empresa àquela vulnerabilidade estratégica e operacional e, invariavelmente, vinha a sua mente a grande diversidade de setores atendidos pela empresa com pouca expressão no faturamento e, por outro lado, a grande dependência econômica de um setor em específico. Diante disso, apresenta-se uma importante decisão a ser tomada pelo administrador: especializar-se em um setor específico ou pulverizar a atuação da empresa em diversos setores?

\section{HISTÓRICO DA EMPRESA}

A Beta Sistemas atua no desenvolvimento de softwares e consultoria em tecnologia da informação. Com sede na Serra Gaúcha, a empresa atende todo o território nacional, sendo REAd | Porto Alegre - Edição 79 - N 3 - setembro/dezembro 2014 - p. 838-856 
Roberta Rodrigues Faoro, Pelayo Munhoz Olea, Sylvia Maria Azevedo Roesch \& Marcelo Faoro de Abreu

que os seus principais clientes estão localizados nos estados do Rio Grande do Sul, Santa Catarina, São Paulo, Bahia e Mato Grosso do Sul.

Os primeiros passos para o surgimento da empresa se deram no ano de 1990 quando o atual proprietário desenvolveu e implantou um software específico para área de fruticultura, mais especificamente a produção de maçãs. Em seguida outros softwares foram desenvolvidos para as áreas de seguros, leilões rurais, comércio atacadista, transporte rodoviário e outros.

A partir do ano de 1996 a empresa passou a ter uma organização mais formal e os primeiros funcionários foram contratados, o que possibilitou uma ampliação para aproximadamente 150 clientes em mais de 30 áreas de atuação. Por ter um foco no desenvolvimento de softwares específicos a quantidade de produtos diferentes passou do número de 80, sendo que muitos possuíam características semelhantes, porém, com especificidades desenvolvidas “sob medida” para cada cliente.

No ano 2000, a empresa realizou a primeira grande reestruturação na sua forma de atuação. A maior modificação foi em termos de produto, onde o enfoque deixou de ser o desenvolvimento de softwares específicos e passou a ser no desenvolvimento de sistemas mais genéricos, assim, os mais de 80 softwares foram substituídos por menos de 10 produtos mais genéricos, porém com possibilidades de parametrização para o atendimento das características próprias de cada cliente. Nesta mesma época, foi agregado também, o serviço de consultoria em TI.

Atualmente, a empresa conta com uma equipe de mais de 30 colaboradores, sendo eles analistas de sistemas, programadores, consultores e agentes administrativos e comerciais.

O mercado onde a empresa atualmente atua é composto, principalmente, por empresas de porte médio nos diferentes setores da economia, entretanto, destaca-se o setor de fruticultura, onde detêm uma participação aproximadamente de 60\% do mercado de softwares para a gestão da produção, comercialização, armazenagem e processamento de maçãs.

Em termos de concorrência a Beta enfrenta as grandes empresas desenvolvedoras de softwares nos clientes que possuem certo padrão nos processos gerenciais e operacionais, entretanto, nas principais áreas de atuação, como a fruticultura, por exemplo, existem apenas dois concorrentes, em função das características de exclusividade dos produtos e serviços comercializados.

REAd | Porto Alegre - Edição 79 - N 3 - setembro/dezembro 2014 - p. 838-856 


\section{A EMPRESA}

Desde sua fundação, a Beta buscou priorizar, em todos os seus processos, a satisfação e o atendimento às demandas de seus clientes, desenvolvendo e customizando os softwares de acordo com as especificidades de cada cliente.

Esta cultura da empresa de "não saber dizer não a clientes e negócios” é fruto das dificuldades administrativas e financeiras encontradas durante os primeiros anos de funcionamento da mesma, que induziram seu fundador, na época, a buscar e aceitar os mais variados projetos relacionados ao desenvolvimento de software.

E quando se fala em variedade de projetos, neste caso, de fato, refere-se à atuação em setores da economia extremamente diferentes e incompatíveis. Como exemplo é possível citar o primeiro software desenvolvido na empresa, que tinha como objetivo gerenciar os processos de controle de qualidade de maçãs e o segundo software que era para a administração de corretoras de seguros, áreas totalmente diferentes e com necessidades diversas.

Os primeiros dez anos de funcionamento da empresa foram marcados por um expressivo crescimento e uma significativa ampliação no número de softwares diferentes desenvolvidos pela Beta, chegando ao ano de 2000 a mais de 80 produtos diferentes, contemplando cada um deles as necessidades específicas dos clientes, que naquela época eram em torno de 200 empresas, dos mais variados portes e setores de atuação.

Esta flexibilidade, que por um lado é positiva, pois atende aos anseios dos clientes, por outro lado acabou sobrecarregando as áreas de desenvolvimento, manutenção e suporte da empresa. Diante disso, e aproveitando uma fase de troca de tecnologia de desenvolvimento de software, no ano de 2000 a empresa iniciou uma significativa reestruturação do seu mix de produtos, procurando reduzir a variedade de sistemas para em torno de uma dezena, com características mais genéricas e com ampla possibilidade de configuração para o atendimento das demandas e funcionalidades específicas dos clientes. Com base no Organograma, representado na Figura 1, é apresentada a estrutura por projetos da empresa Beta Sistemas.

REAd | Porto Alegre - Edição 79 - N 3 - setembro/dezembro 2014 - p. 838-856 
Roberta Rodrigues Faoro, Pelayo Munhoz Olea, Sylvia Maria Azevedo Roesch \& Marcelo Faoro de Abreu

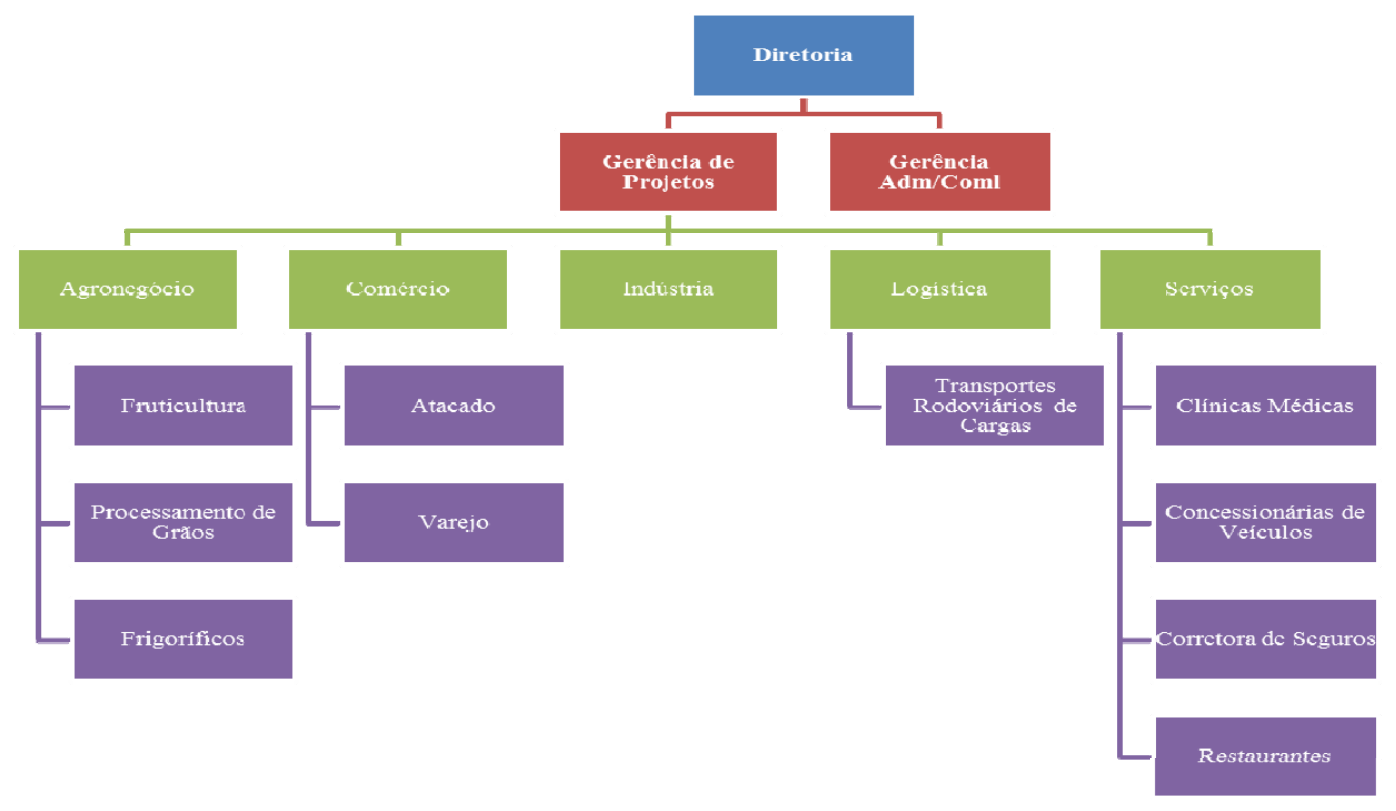

Figura 1 - Organograma da Beta Sistemas Fonte: dados fornecidos pela empresa

Como resultado da reestruturação iniciada em 2000 a empresa chegou ao ano de 2010 com uma categorização mais clara dos setores econômicos atendidos, os quais são apresentados no Quadro 1, juntamente com o número de clientes e sua respectiva participação no faturamento total.

Fica evidente, nos dados apresentados no Quadro 1, que o principal setor gerador de faturamento para a empresa é o setor de Fruticultura, onde os clientes deste setor foram responsáveis, no ano de 2010, por 58,7\% do faturamento global da empresa. Esta expressividade encontrada neste setor deve-se a alguns fatores principais:

1) A Beta é detentora, exclusiva, de um software específico voltado para este setor. Este software além de bastante competitivo em termos comerciais é requisito operacional básico para o funcionamento de algumas empresas do setor em questão;

2) O porte e a profissionalização encontrados nas empresas atuantes neste setor viabilizam a prestação de serviços com maior valor agregado como consultorias, modelagem de processos e implementação de módulos complementares aos softwares utilizados pelas mesmas;

3) As empresas deste setor, em geral, possuem diversas unidades produtivas e, muitas vezes, atuam em diversos elos de sua cadeia de suprimentos, oportunizando à Beta um crescimento constante de faturamento dentro dos próprios clientes;

REAd | Porto Alegre - Edição 79 - N 3 - setembro/dezembro 2014 - p. 838-856 
Diferenciação e foco para obtenção de vantagem competitiva: o caso da Beta Sistemas

4) Há uma grande semelhança nos processos e na forma de trabalho dos clientes deste setor, viabilizando otimizações de trabalho de desenvolvimento de softwares.

Quadro 1 - Participação no Faturamento por Setor Econômico no ano de 2010

\begin{tabular}{|l|c|c|}
\hline Setor & Número de Clientes & Participação no Faturamento \\
\hline Fruticultura & 73 & $58,7 \%$ \\
\hline Comércio Varejista & 118 & $21,3 \%$ \\
\hline Comércio Atacadista & 29 & $6,9 \%$ \\
\hline Restaurantes & 23 & $4,6 \%$ \\
\hline Transporte Rodoviário de Cargas & 12 & $2,3 \%$ \\
\hline Indústria & 3 & $2,1 \%$ \\
\hline Processamento e Armazenagem de Grãos & 5 & $0,8 \%$ \\
\hline Corretoras de Seguros & 21 & $0,7 \%$ \\
\hline Frigoríficos & 2 & $0,6 \%$ \\
\hline Concessionárias de Veículos & 3 & $0,4 \%$ \\
\hline Clínicas Médicas & 2 & $0,2 \%$ \\
\hline Outros & 37 & $1,4 \%$ \\
\hline
\end{tabular}

Fonte: dados fornecidos pela empresa

No mesmo período onde foi implementada a reestruturação dos produtos de software, a empresa também incorporou novos serviços ao seu portfólio, com destaque para a consultoria em tecnologia da informação e modelagem de processos, isso possibilitou um incremento de cerca de 15\% na receita a partir dos clientes já existentes na empresa.

Portanto, atualmente os serviços prestados pela empresa compreendem as diversas etapas de concepção, consultoria, análise, desenvolvimento, implantação e manutenção de sistemas de informação em empresas dos mais variados segmentos.

No que se refere à participação de cada tipo de serviço no faturamento da empresa. Observa-se no Quadro 2 que a grande concentração está nos serviços diretamente relacionados com a atividade principal e original da empresa, ou seja, os softwares.

Quadro 2 - Participação no Faturamento por Serviço em 2010

\begin{tabular}{|l|c|}
\hline Tipo de Serviço & Participação no Faturamento \\
\hline Licenciamento/Implantação de Softwares & $39,2 \%$ \\
\hline Manutenção de Softwares & $29,6 \%$ \\
\hline Customização de Softwares & $12,7 \%$ \\
\hline Consultoria em TI & $11,9 \%$ \\
\hline Modelagem de Processos & $6,6 \%$ \\
\hline
\end{tabular}

Fonte: dados fornecidos pela empresa

Os produtos e serviços oferecidos pela empresa, listados no Quadro 2, são executados por uma equipe composta por analistas de sistemas, analistas de suporte, programadores de REAd | Porto Alegre - Edição 79 - N 3 - setembro/dezembro 2014 - p. 838-856 
Roberta Rodrigues Faoro, Pelayo Munhoz Olea, Sylvia Maria Azevedo Roesch \& Marcelo Faoro de Abreu

computadores e consultores. Esta equipe é dividida em três grupos principais onde cada grupo é responsável por um conjunto de sistemas e atendem áreas pré-determinadas, dentre aquelas áreas listadas na Figura 1. A distribuição das tarefas é baseada no número de solicitações dos setores, sendo que duas equipes são destinadas para atender os setores de comércio e serviço e a outra equipe atende os demais setores: agronegócio, indústria, logística e outros.

A mensuração e apropriação dos custos inerentes a cada atividade é realizada com base em horas alocadas. Com base nestes dados é possível, portanto, estabelecer um comparativo de utilização de recursos (horas) para cada setor econômico atendido assim como para cada tipo de serviço. No Quadro 3 é apresentado uma síntese do percentual de horas dedicadas a cada setor econômico durante o ano de 2010.

Quadro 3 - Comparativo de Horas Alocadas por Setor em 2010

\begin{tabular}{|l|c|c|}
\hline Setor & Número de Clientes & Horas Alocadas \\
\hline Comércio Varejista & 118 & $42,70 \%$ \\
\hline Fruticultura & 73 & $16,30 \%$ \\
\hline Restaurantes & 23 & $13,60 \%$ \\
\hline Comércio Atacadista & 29 & $8,30 \%$ \\
\hline Transporte Rodoviário de Cargas & 12 & $7,80 \%$ \\
\hline Indústria & 3 & $3,20 \%$ \\
\hline Frigoríficos & 2 & $2,30 \%$ \\
\hline Concessionárias de Veículos & 3 & $1,70 \%$ \\
\hline Corretoras de Seguros & 21 & $0,70 \%$ \\
\hline Processamento e Armazenagem de Grãos & 5 & $0,20 \%$ \\
\hline Clínicas Médicas & 2 & $0,10 \%$ \\
\hline Outros & 37 & $3,10 \%$ \\
\hline
\end{tabular}

Fonte: dados fornecidos pela empresa

Por fim, o Quadro 4 apresenta a proporção de alocação de horas trabalhadas por tipo de atividade.

Quadro 4 - Alocação de Horas por Tipo de Serviço em 2010

\begin{tabular}{|l|c|}
\hline Tipo de Serviço & Participação no Faturamento \\
\hline Licenciamento/Implantação de Softwares & $31,60 \%$ \\
\hline Manutenção de Softwares & $22,30 \%$ \\
\hline Customização de Softwares & $21,50 \%$ \\
\hline Consultoria em TI & $11,90 \%$ \\
\hline Modelagem de Processos & $12,70 \%$ \\
\hline
\end{tabular}

Fonte: dados fornecidos pela empresa

\section{O DILEMA}

Mesmo passando por uma reestruturação administrativa e operacional entre os anos de 2000 e 2010, podendo destacar no nível operacional a formalização de processos, os testes e REAd | Porto Alegre - Edição 79 - N 3 - setembro/dezembro 2014 - p. 838-856 
Diferenciação e foco para obtenção de vantagem competitiva: o caso da Beta Sistemas

validação de softwares e na área administrativa a participação dos colaboradores nas ideias de novos processos e produtos, a empresa ainda apresenta alguns problemas e indefinições estratégicas que preocupam e angustiam o seu gestor.

Uma das principais preocupações de Roberto é relacionada com a sobrecarga de trabalho, que pode ser observada no Quadro 3, com as quais as equipes convivem permanentemente. Esta sobrecarga aparentemente é fruto, ainda, de uma excessiva diversificação dos setores atendidos pela empresa e vem limitando o crescimento da empresa em função da impossibilidade de atendimento no tempo requerido pelos clientes.

Em uma das reuniões semanais com os gerentes de projetos da empresa Roberto, mais uma vez evidencia que algo deve ser mudado para que a Beta possa ter o ritmo de crescimento desejável. Roberto inicia a reunião comunicando a assinatura de um novo contrato com uma empresa já cliente, para o desenvolvimento e implantação de um novo sistema:

- “Assinamos o contrato de desenvolvimento do novo sistema de distribuição de frutas para a filial da Bahia da empresa Agrox, que já é um dos nossos principais clientes”.

João, que é o gerente de projetos responsável pelo grupo que atende os clientes dos setores de fruticultura, frigoríficos e processamento e armazenagem de grãos, alerta sobre o grande risco de não conseguir executar o projeto a tempo:

- “Mas Roberto, nossa equipe está sobrecarregada, não sei se vamos conseguir entregar este projeto a tempo. Estamos tentando contratar mais programadores, mas você sabe como está o mercado, está muito difícil encontrar programadores disponíveis e mesmo que consigamos, até que sejam treinados o projeto estará comprometido”.

Roberto argumenta:

- "Mas eu não poderia deixar de assumir este contrato, primeiro por que é do setor de fruticultura, nossa principal fonte de receita, segundo por que é de um já tradicional cliente nosso e, caso não possamos atendê-lo podemos perder toda a conta da Agrox, e isso pode abrir espaço para o surgimento de concorrentes, que hoje não temos neste setor”.

Roberto continua:

- "O fato é que temos de executar o projeto, e no prazo! Que alternativas nós temos? Remanejar programadores de outro grupo? Fazer alguma parceria com outras empresas?”.

Gustavo, o gerente de projetos de outro grupo contesta:

REAd | Porto Alegre - Edição 79 - N 3 - setembro/dezembro 2014 - p. 838-856 
Roberta Rodrigues Faoro, Pelayo Munhoz Olea, Sylvia Maria Azevedo Roesch \& Marcelo Faoro de Abreu

- "Remanejar funcionários de outros grupos é inviável, todos também estão trabalhando no limite, se tirar alguém não vamos conseguir atender os demais projetos no prazo”.

Roberto questiona:

- “Mas afinal, onde está o nosso gargalo? Por que estamos trabalhando no limite?”.

João esclarece:

- "O problema é que atendemos muitos setores diferentes, e sabemos que muitos deles são deficitários. A maioria dos sistemas destes setores são praticamente commodities, geram pouco valor agregado e consomem muitos recursos. Resumindo, estamos investindo nosso esforço em setores que não dão retorno em detrimento da fruticultura, por exemplo, onde temos grande vantagem competitiva”.

O trecho do diálogo apresentado acima demonstra, claramente, que é necessário que sejam tomadas decisões radicais em relação ao posicionamento estratégico da empresa, sob pena de inviabilizar o crescimento e até mesmo o futuro da Beta Sistemas. A estratégia atualmente adotada pela empresa, notadamente, vêm comprometendo o seu desempenho operacional e expondo-a excessivamente a riscos de perda de mercado e de não aproveitamento de oportunidades em função das limitações operacionais. Diante disso, é necessário um reposicionamento estratégico.

REAd | Porto Alegre - Edição 79 - N 3 - setembro/dezembro 2014 - p. 838-856 


\section{ANEXO 1 - NOTAS DE ENSINO}

\section{Utilização recomendada}

Este caso foi elaborado para ser utilizado como ferramenta auxiliar de ensino, principalmente em disciplinas relacionadas à estratégia na graduação e pós graduação lato sensu do curso de administração. Recomenda-se que o caso seja fornecido antecipadamente aos alunos.

Sugere-se a estrutura a seguir (em torno de 3 horas de duração):

- $1 \mathrm{~h}$ - Apresentação e/ou discussão de temas correlatos, após 15 minutos de intervalo.

- 30 min - Discussão do caso em grupos de no máximo 4 alunos.

- 30 min - Discussão do caso em plenária.

- 30 min - Associação com a teoria referente à disciplina.

\section{Objetivo de aprendizagem}

O caso da empresa Beta Sistemas, conforme a sua história e suas características próprias proporcionam elementos para uma reflexão e discussão sobre posicionamentos estratégicos, assim, o objetivo de aprendizagem pretendido com este caso de ensino concentra-se nos elementos relacionados às escolhas estratégicas da organização. A título de orientação, as seguintes reflexões, ou outras, poderão ser utilizadas para subsidiar as decisões sobre o posicionamento estratégico da empresa:

1) Centralizar seus esforços na busca de eficiência produtiva, na ampliação do volume de produção e na minimização de gastos.

2) Investimento pesado em pesquisa e desenvolvimento, com a finalidade de criar diferenciais para o cliente.

3) Análise da dimensão dos clientes que afetam a evolução dos serviços e também colocam a empresa sob pressão frente a preços e prazos.

4) Escolher um alvo restrito, no qual, por meio da diferenciação ou do custo, a empresa se especializará atendendo a segmentos ou nichos específicos.

5) Definição de uma boa estratégia, para conhecer bem o setor e as características que governam as suas forças competitivas.

6) Análise dos recursos estratégicos ou uma combinação de recursos superiores para obter vantagem competitiva.

\section{SUGESTÃO DE QUESTÕES PARA ANÁLISE DO CASO}

1) Qual a relação entre os problemas enfrentados pela Beta Sistemas e seu processo de crescimento?

2) No seu ponto de vista a decisão de assinar o contrato com a Agrox foi uma decisão estratégica acertada? Justifique.

3) Pode-se afirmar que o software de fruticultura é um recurso estratégico para a obtenção de vantagens competitivas para a empresa Beta Sistemas? Por quê?

4) Porter (1980), identificou três estratégias genéricas que podem ser usadas individualmente ou em conjunto para criar uma posição sustentável a longo prazo. Alguma delas poderia ser considerada neste caso de ensino? Justifique.

5) O que deve ser feito para solucionar o problema?

\section{ALTERNATIVAS PARA ANÁLISE}

\section{Alternativa 1 - Estratégia e Competitividade}

A questão central deste estudo é referente ao posicionamento estratégico que a Beta Sistemas, através de seu gestor, deve escolher para poder atingir os objetivos e metas. Na visão de Porter (1996), estratégia significa fazer as coisas diferentes de seus concorrentes ou a 
mesma coisa que seus concorrentes, mas proporcionando maior valor agregado para os consumidores - estratégia não corresponde simplesmente a eficiência ou eficácia operacional.

Já Tidd et al. (2008) entendem que a vantagem competitiva pode advir de tamanho ou patrimônio, entre outros fatores, porém, o cenário está gradativamente mudando em favor daquelas organizações que conseguem mobilizar conhecimento e avanços tecnológicos, criando novidades em suas ofertas de produtos e serviços e nas formas como criam e lançam estas ofertas. A inovação contribui de diversas formas. Produtos novos permitem capturar e reter novas fatias de mercado, além de aumentar a lucratividade em tais mercados.

Além disso, Porter (1985) acredita que há dois tipos básicos de vantagem competitiva que uma empresa pode possuir: custos baixos ou diferenciação. Assim, uma boa decisão para a empresa Beta Sistemas, poderia ser adotar a estratégia de diferenciação e foco no setor de fruticultura, em virtude de ser este o setor que estão concentrados os clientes com maior potencial de agregação de valor. Conforme é transcrito no caso de ensino:

[...] Outro ponto a ser destacado nesta análise é a quantidade de clientes do setor de fruticultura que totaliza 73 empresas, ou seja, 22,3\% do número total de clientes da empresa. Assim, é possível verificar que apenas 22,3\% dos clientes da empresa são responsáveis por 58,7\% de sua receita total.

Tendo como objetivo geral a especialização e qualificação da equipe da empresa para este segmento, prestando assim, um serviço de excelência para os clientes.

Para Porter (1980), as empresas em geral podem adotar três tipos de estratégia competitiva, conhecidas como estratégias genéricas para enfrentar as cinco forças e criar uma posição defensável em longo prazo e superar os concorrentes, estas estratégias são a liderança no custo total, a diferenciação e o enfoque.

Liderança no custo total - esta estratégia, basicamente, visa obter vantagens competitivas pela oferta de produtos e serviços (em geral padronizados) a custos mais baixos do que os concorrentes (PORTER, 1980). Para que sejam atingidas as metas de liderança no custo é necessária a construção agressiva de instalações em escala eficiente, constante busca de reduções de custos pela experiência, rígido controle dos custos e despesas gerais, minimização dos custos de pesquisa e desenvolvimento, assistência, força de vendas, publicidade, etc. (PORTER, 1999). Esta estratégia produz para a empresa que a adota a possibilidade de obtenção de retornos acima da média de seu setor, apesar da presença das forças competitivas. A posição de baixo custo possibilita a defesa contra a rivalidade dos concorrentes, porque seus custos inferiores possibilitam a manutenção da rentabilidade quando os concorrentes já tiverem consumido seus lucros durante a competição. A empresa é defendida do poder dos compradores porque estes somente conseguem exercer poder de barganha com base em concorrentes mais eficientes. Em relação ao poder dos fornecedores, o baixo custo pode trazer maior flexibilidade para enfrentar o aumento dos insumos. A estratégia de baixo custo também proporciona a criação de barreiras de entradas em função da sua economia de escala. Por fim, a posição de baixo custo proporciona o posicionamento da empresa em uma posição mais confortável em relação aos produtos substitutos de seus concorrentes (PORTER, 1999).

Diferenciação - esta estratégia busca alcançar vantagens pela introdução de um ou mais elementos de diferenciação nos produtos e serviços, que justifiquem preços mais elevados (PORTER, 1980). A diferenciação pode se dar de diferentes formas, tais como projeto ou imagem da marca, tecnologia, peculiaridades, produtos ou serviços personalizados, rede de distribuição, dentre outros (PORTER, 1999). O autor, ainda destaca que, mesmo não sendo o alvo estratégico primário, os custos não devem ser ignorados. A estratégia da diferenciação proporciona defesa contra a rivalidade competitiva através da fidelidade dos clientes em relação à marca e da menor sensibilidade destes clientes quanto aos preços. A fidelidade dos clientes é, também, considerada como uma barreira de entrada para novos

REAd | Porto Alegre - Edição 79 - N 3 - setembro/dezembro 2014 - p. 838-856 
competidores. A diferenciação possibilita a prática de preços mais elevados, com isso, gerando margens superiores que reduz a vulnerabilidade perante os fornecedores e também ameniza o poder dos compradores por estes terem as disposições alternativas compatíveis, assim, tornam-se menos sensíveis aos preços. Além disso, por obterem a fidelidade dos clientes, as empresas com perfil de diferenciação ficam menos expostas à concorrência de produtos substitutos do que seus competidores (PORTER, 1999).

Enfoque - procura obter vantagens competitivas ou pela oferta de produtos e serviços com menores custos, ou pela diferenciação dos mesmos, mas em um segmento de mercado mais localizado ou restrito (PORTER, 1980). Esta estratégia baseia-se no pressuposto de que a empresa pode atender seu alvo estratégico específico mais efetiva ou eficientemente do que os concorrentes que estão atuando de forma mais ampla (PORTER, 1999). Como consequência, a empresa acaba atingindo a diferenciação por especializar-se e atender de forma mais adequada as necessidades do seu alvo específico, ou os custos podem cair em função da especialização, ou ambos (PORTER, 1999). Ainda sobre estratégia competitiva, Porter (1985) afirma que esta, em uma empresa em geral, é desdobrada em estratégias funcionais como as estratégias de marketing, de produção, financeira e tecnológica, buscandose compor um todo coeso e harmônico de planos e ações que propiciem a aquisição de vantagens competitivas pela melhoria dos processos de negócios ou de elementos na "cadeia de valor" (PORTER, 1985).

Para Mintzberg et al. (2009), existem dois conjuntos de estratégias competitivas. O primeiro conjunto é baseado no princípio da diferenciação e procura concentrar-se no produto oferecido, adotando a perspectiva do cliente, existindo apenas quando a pessoa percebe alguma característica que agregue valor ao produto. Já no segundo caso, o conjunto de estratégias é o escopo, e busca focar no mercado atendido, adotando a perspectiva do produtor, existindo apenas na mente coletiva da organização - em termos de como ela difunde e desagrega seus mercados, ou seja, como define sua segmentação. Segundo os autores, na estratégia de diferenciação a organização busca diferenciar-se num mercado competitivo atuando para distinguir seus produtos e serviços dos produtos e serviços dos concorrentes. Busca adotar um conjunto de estratégias que busca de forma extensiva que se identifique o que a empresa tem de fundamentalmente distinto no mercado, ou seja, como ela pode ser percebida diferente pelos clientes. Esta diferenciação pode ser realizada de seis maneiras básicas: (1) diferenciação de preço, (2) diferenciação de imagem, (3) diferenciação de suporte, (4) diferenciação de qualidade, (5) diferenciação de design e (6) não diferenciação. A segunda dimensão para diferenciar o negócio da empresa é o escopo dos produtos e serviços oferecidos considerando a extensão dos mercados para os quais eles são vendidos. Esta diferenciação pode ser feita de quatro formas básicas: (1) massa, (2) segmentação, (3) nicho e (4) personalização. Nesse caso, o conjunto de estratégias busca identificar que mercados as empresas estão buscando, segundo a visão delas.

Por fim, segundo Porter (1989), a essência da formulação da estratégia competitiva é relacionar uma empresa ao meio ambiente competitivo, sendo que esse, por sua vez, é função da estrutura na qual a empresa compete. Porter (1985) indica que cinco forças determinam a dinâmica da competição nas empresas: a entrada de novos concorrentes, a ameaça de substitutos, o poder de barganha dos clientes, o poder de barganha dos fornecedores e a rivalidade entre os concorrentes atuais. As cinco forças, variam de uma empresa para outra e suas intensidades estabelecem, para cada uma delas, o potencial de lucro final que é medido como retorno de longo prazo sobre o capital investido. Elas determinam a lucratividade, uma vez que fixam os preços que as empresas podem cobrar os custos que têm de suportar e o investimento necessário para competir (PORTER, 1985; MORAES; ZILBER 2004).

REAd | Porto Alegre - Edição 79 - N 3 - setembro/dezembro 2014 - p. 838-856 
Novos entrantes - são novas empresas que entram em um mercado trazendo consigo novas capacidades, desejo de ganhar uma parcela do mercado e normalmente recursos substanciais. O autor aponta como resultados desta entrada possíveis quedas nos preços ou inflação nos custos dos participantes, reduzindo, assim, a rentabilidade (PORTER, 1999). O autor ainda destaca que a ameaça de entrada depende das barreiras de entrada existentes, conjugada com a reação esperada pelo novo concorrente em relação aos concorrentes já existentes. Intensidade da rivalidade entre os concorrentes - refere-se à disputa por posição entre os concorrentes usando para isso, táticas como concorrência de preços, batalhas publicitárias, introdução de produtos e aumento dos serviços ou das garantias aos clientes. A rivalidade ocorre quando um ou mais concorrentes sentem-se pressionados ou percebem a oportunidade de melhorar sua posição. Pressão dos produtos substitutos - os produtos substitutos reduzem os retornos potenciais de uma indústria, colocando um teto nos preços que as empresas podem fixar como lucro. Quanto mais atrativa a alternativa de preçodesempenho oferecida pelos produtos substitutos, mais firme será a pressão sobre os lucros da empresa (PORTER, 1999). Poder de negociação dos compradores - os compradores competem com a indústria forçando os preços para baixo, barganhando por melhor qualidade ou mais serviços e jogando os concorrentes uns contra os outros. O poder de cada grupo importante de compradores depende de certas características quanto à sua situação no mercado e da importância relativa de suas compras em comparação com seus negócios totais (PORTER, 1999). Poder de negociação dos fornecedores - os fornecedores podem exercer poder de negociação sobre os participantes de uma indústria ameaçando elevar preços ou reduzir a qualidade dos bens e serviços fornecidos. Fornecedores poderosos podem sugar a rentabilidade de uma indústria incapaz de repassar os aumentos de custos em seus próprios preços (PORTER, 1999).

\section{Alternativa 2 - Resource based view (RBV)}

Pode-se ainda, considerar a resource based view (RBV), em português, Visão Baseada em Recursos (PENROSE, 1959; BARNEY, 1991). A RBV é uma abordagem da gestão estratégica, que analisa a forma como os recursos podem conduzir à vantagem competitiva. A vantagem competitiva é a capacidade de criar mais valor do que os rivais, e, portanto, gerar maiores retornos sobre o investimento. Vantagem competitiva sustentável requer benefícios duradouros através de recursos que não são facilmente imitados (KILLEN et al., 2012).

Associado a isso, o caso de ensino deixa claro que o software de fruticultura é um recurso estratégico para a empresa Beta Sistemas, no momento que apresenta os resultados do faturamento do setor e os respectivos fatores:

[...] que o principal setor gerador de faturamento para a empresa é o setor de Fruticultura, onde os clientes deste setor foram responsáveis, no ano de 2010, por 58,7\% do faturamento global da empresa. Esta expressividade encontrada neste setor deve-se a alguns fatores principais:

1) A Beta é detentora, exclusiva, de um software específico voltado para este setor. Este software além de bastante competitivo em termos comerciais é requisito operacional básico para o funcionamento de algumas empresas do setor em questão;

2) $O$ porte e a profissionalização encontrados nas empresas atuantes neste setor viabilizam a prestação de serviços com maior valor agregado como consultorias, modelagem de processos e implementação de módulos complementares aos softwares utilizados pelas mesmas;

3) As empresas deste setor, em geral, possuem diversas unidades produtivas e, muitas vezes, atuam em diversos elos de sua cadeia de suprimentos, oportunizando para a Beta um crescimento constante de faturamento dentro dos próprios clientes;

4) Há uma grande semelhança nos processos e na forma de trabalho dos clientes deste setor, viabilizando otimizações de trabalho de desenvolvimento de softwares.

Apesar da visão de Penrose, de certa forma ser um tanto restrita aos bens tangíveis, como plantas, equipamentos, terras, matérias-primas, recursos humanos disponíveis e outros,

REAd | Porto Alegre - Edição 79 - N 3 - setembro/dezembro 2014 - p. 838-856 
sua grande contribuição foi salientar que a fonte de individualidade de uma firma não reside no seu conjunto de recursos, mas sim na forma como estes são usados, ou seja, nos serviços gerados. Em outras palavras, apesar dos recursos serem importantes, é a forma como eles serão usados que definirá a vantagem competitiva de uma firma sobre as demais (ALVES; BOMTEMPO; COUTINHO, 2005).

Para William et al. (2010), a obra de Edith Penrose nos anos 50, foi altamente considerada como uma mudança na prática da RBV como ela explorou a ligação entre os recursos e o crescimento da empresa. Em seu trabalho, ela enfatizou que as empresas devem ser conceituadas como um quadro administrativo composto por um conjunto de recursos e, portanto, ela concluiu que o crescimento de uma empresa é limitado por este aspecto crucial da empresa (WILLIAM et al., 2010). Penrose argumentou que o crescimento externo e interno posterior de uma empresa por meio de fusões, aquisições e diversificação, é devido à forma como os recursos são explorados (NEWBERT, 2007).

Barney (1991) concorda e amplia a perspectiva original de Penrose, afirmando que o conjunto de recursos da firma não é somente uma lista de fatores, mas o processo de interação entre estes recursos, bem como seus efeitos sobre a organização. Portanto, esses recursos podem ser vistos como pacotes de ativos tangíveis e intangíveis, como habilidades de gestão de uma empresa, seus processos, rotinas organizacionais, informações e os conhecimentos sob seu controle (BARNEY; WRIGHT; KETCHEN, 2001). Dito de outra forma, os recursos são valiosos quando eles ajudam a melhorar a eficiência e eficácia da empresa (BARNEY, 1991).

Sendo assim, as condições sob as quais os recursos são valiosos são dependentes do contexto (BARNEY, 1991, 2001; PRIEM; BUTLER, 2001). O valor de um determinado recurso é determinado em relação a tais condições como estratégia organizacional e ambientes externos (PRIEM; BUTLER, 2001). Com base na perspectiva de Penrose (1959), Barney (1991, 2001) e Peteraf (1993) sugerem que a vantagem competitiva está ligada ao fato das empresas possuírem um conjunto de recursos mais apropriados às demandas colocadas pelos mercados onde elas atuam, obtendo assim vantagem competitiva.

Segundo Barney $(1991,2001)$, para que os recursos se tornem fonte de vantagem competitiva, eles devem possuir as seguintes características: Valor: os recursos devem permitir que as empresas conservem ou executem as estratégias que melhoram sua eficiência ou eficácia; devem viabilizar a exploração de oportunidades ou a neutralização das ameaças expostas no ambiente; Raridade: os recursos devem ser tão raros quanto as empresas competidoras numa determinada indústria para garantir a sustentabilidade da vantagem competitiva; Imperfeitamente imitáveis: empresas que não possuem um determinado recurso devem enfrentar dificuldade financeira para obtê-la em relação àquelas que já possuem o recurso, devido a condições históricas únicas (pioneirismo de algumas empresas frente ao recurso), ambiguidade causal (ignorância da utilização correta do recurso) ou simplesmente por complexidade social; e Imperfeitamente substituíveis: quando não existem recursos capazes de implementarem as mesmas estratégias, ainda que de forma similar, ou quando seus resultados sucumbem às características que levam o recurso a ser gerador de valor estratégico. Finalmente os recursos, valiosos, raros e difíceis de imitar podem ser uma fonte sustentada de vantagem competitiva na medida em que não há recursos estrategicamente equivalentes (BARNEY, 2001).

Por outro lado, na visão de Peteraf (1993), para que a organização possa criar e sustentar a vantagem competitiva quatro macro-condições devem estar simultaneamente presentes: Heterogeneidade: condição na qual uma empresa detém um recurso que possui características de valor superior às da concorrência. Esta característica pode ser observada quando a presença de recursos estratégicos é limitada numa empresa em termos de

REAd | Porto Alegre - Edição 79 - N 3 - setembro/dezembro 2014 - p. 838-856 
Roberta Rodrigues Faoro, Pelayo Munhoz Olea, Sylvia Maria Azevedo Roesch \& Marcelo Faoro de Abreu

quantidade, ou ela se esvai em relação ao tempo. Portanto, os recursos devem ser fixos (ou seja, não podem ser expandidos) ou quase fixos (não podem ser expandidos rapidamente). Com estas características, os recursos tendem a ser mais escassos e, portanto, os tornam insuficientes para atender toda a demanda das empresas, e com isto permitir que recursos com menos capacidade de geração de valor são então utilizados pela concorrência para suprir a demanda residual. Esta característica gera lucros para as empresas detentoras do recurso de valor, fazendo com que exista o que se chamam Lucros de Monopólio; Limitações ex-ante a competição: condição na qual, antes do recurso gerar vantagem competitiva e posição privilegiada da empresa, exista uma competição limitada por este recurso. Segundo a autora, um recurso eficiente produzirá mais valor quanto menor for a competição e os custos envolvidos para a aquisição deste, pois a competição geraria uma erosão e dissipação dos possíveis lucros envolvidos com o recurso; Limitações ex-post à competição: condição na qual, depois de adquirida a posição esperada e o recurso gerar vantagem competitiva, ele deverá ser imperfeitamente imitável e substituível, de tal forma que preserve os lucros proporcionados com o recurso superior, garantindo assim a sua condição de heterogeneidade; e Mobilidade Imperfeita: condição na qual um recurso possa gerar vantagem competitiva sustentável, por ser mantido dentro da empresa. Esta condição se deve a alguns fatores como a dificuldade para se definirem direitos de propriedade, recursos possuírem características de maior agregação de valor se utilizados dentro da empresa do que em seus concorrentes, maior agregação de valor se utilizado em conjunto com outros recursos da empresa e elevados custos de transferência.

Além disso, uma empresa que alcança uma vantagem competitiva cria mais valor econômico do que seus concorrentes (PETERAF; BARNEY, 2003). Os autores sugerem ainda, que o valor econômico é geralmente criado através da produção de produtos e/ou serviços querem sejam com maiores benefícios com o mesmo custo em relação aos concorrentes (ou seja, a vantagem competitiva baseada em diferenciação) ou os mesmos benefícios a um custo menor em relação aos concorrentes (eficiência baseada em vantagem competitiva). Porque benefícios superiores tendem a aumentar a lealdade do cliente e qualidade percebida (ZOU; FANG; ZHAO, 2003), uma empresa que pode explorar as suas capacidades de recursos para atingir efetivamente uma vantagem competitiva baseada em diferenciação deve ser capaz de melhorar o seu desempenho em relação aos concorrentes, vendendo mais unidades na mesma margem (ou seja, a paridade de preços) ou vendendo o mesmo número de unidades em uma maior margem (ou seja, o preço premium).

Portanto, uma estrutura de custo superior permite uma maior flexibilidade de preços, bem como a capacidade de aumentar o excedente disponível (ZOU; FANG; ZHAO, 2003), uma empresa que pode explorar as suas capacidades de recursos para atingir efetivamente uma vantagem competitiva baseada em eficiência deve ser capaz de melhorar o seu desempenho em relação aos concorrentes, vendendo mais unidades na mesma margem (ou seja, baixo preço) ou vendendo o mesmo número de unidades em uma maior margem (ou seja, a paridade preço). Em ambos os casos, é lógico supor que uma empresa que alcança uma vantagem competitiva, seja na forma de maiores benefícios com o mesmo custo ou os mesmos benefícios a um custo menor, será capaz de melhorar seu desempenho de forma que seus concorrentes não podem (PORTER, 1985).

Por fim, com base na abordagem da RBV, entende-se que a valorização dos atributos internos da firma deve servir como fonte de vantagem competitiva sustentável e que uma maior dotação de alguns recursos agrega valor aos produtos e serviços produzidos e oferecidos ao mercado (OLIVEIRA, 2001).

\section{COMENTÁRIOS FINAIS}

REAd | Porto Alegre - Edição 79 - N 3 - setembro/dezembro 2014 - p. 838-856 
Diferenciação e foco para obtenção de vantagem competitiva: o caso da Beta Sistemas

Em busca de comentários finais, é que as duas abordagens sugeridas não são necessariamente dicotômicas, mas podem ser complementares, pois, a primeira abordagem estaria relacionada aos fatores externos, já a segunda cita fatores internos. Para Porter (1999), independentemente da pressão exercida pelas forças competitivas externas, o estrategista empresarial necessita ter por foco encontrar formas de melhor defender a organização contra estas forças ou influenciálas em seu favor. Sob uma perspectiva aprofundada, ficou evidenciado que tais formas podem ser de fato, traduzidas pelo gerenciamento efetivo dos recursos de gerenciamento interno, sejam eles, de capital físico, humano ou organizacional.

\section{ESTUDOS COMPLEMENTARES}

FILHO, G. A. L.; CARVALHO, F. M. de.; ANTONIALLI, L. M. Heterogeneidade de desempenho das pequenas empresas Brasileiras: uma abordagem da visão baseada em recursos (VBR). REAd, Porto Alegre, v. 73, n. 3, p. 631-650, set./dez. 2012.

Link de acesso: http://seer.ufrgs.br/index.php/read/article/view/35433/22971

LEITE, A. L. S.; FIATES, G. G. S.; LIMA, M. A. de. Fatores condicionantes da vantagem competitiva nos postos de combustíveis de Florianópolis. Rebrae. Revista Brasileira de Estratégia, Curitiba, v. 6, n. 1, p. 37-44, jan./abr. 2013.

Link de acesso: http://www2.pucpr.br/reol/index.php/REBRAE?dd1=7665\&dd99=view

\section{REFERÊNCIAS BIBLIOGRÁFICAS DAS NOTAS DE ENSINO}

ALVES, F. C.; BOMTEMPO, J. V.; COUTINHO, P. Competências para Inovar na indústria petroquímica brasileira. Revista Brasileira de Inovação, v. 4, n. 2, 2005.

BARNEY, J.B. Firm resources and sustained competitive advantage. Journal of Management, v. 17, p. 99-120, 1991.

. Is the resource-based 'view' a useful perspective for strategic management research? Yes. Academy of Management Review, v. 26, p. 41-56, 2001.

BARNEY, J. B.; WRIGHT, M.; KETCHEN JR., D. J. The resource-based view of the firm: Ten years after 1991. Journal of Management, v. 27, p. 625-641, 2001.

KILLEN, C. , JUGDEV, K. , DROUIN, N., PETIT, Y. Advancing project and portfolio management research: Applying strategic management theories. International Journal of Project Management, 2012, v. 30, n. 5, p.525-538 , 2012.

MINTZBERG, H., LAMPEL, J., QUINN, J., GHOSHAL, S. O Processo da Estratégia. Porto Alegre: Bookman, 2009.

MORAES, C. A.; ZILBER, M. A. Estratégia e Vantagem Competitiva: Um Estudo do Setor Petroquímico Brasileiro. Revista de administração Mackenzie, v. 5, n.1, p. 165-195, 2004.

REAd | Porto Alegre - Edição 79 - N 3 - setembro/dezembro 2014 - p. 838-856 
Roberta Rodrigues Faoro, Pelayo Munhoz Olea, Sylvia Maria Azevedo Roesch \& Marcelo Faoro de Abreu

NEWBERT, S. Empirical Research on the Resource-Based View of the Firm: An Assessment and Suggestions for Future Research. Strategic Management Journal, v. 28, n. 2, p. 121-146, 2007.

OLIVEIRA JR., M.M. Competências essenciais e conhecimento na empresa. In: FLEURY, M.T.L.; OLIVEIRA JR., M.M. Gestão Estratégica do Conhecimento: integrando aprendizagem, conhecimento e competências. São Paulo: Atlas, 2001.

PENROSE, E. T. The theory of the growth of the firm. New York: Wiley, 1959.

PETERAF, M. A. The cornerstones of competitive advantage: a resource based view. Strategic Management Journal, v. 14, 179-191, 1993.

PETERAF, M. A.; BARNEY, J. B. Unraveling the resourcebased tangle. Managerial and Decision Economics, v. 24, p. 309-323, 2003.

PORTER, M. E. Competitive strategy. New York: Free Press, 1980.

. Competitive advantage. New York: Free Press, 1985.

A vantagem competitiva das nações. Rio de Janeiro: Campus, 1989.

. What is Strategy? Harvard Business Review, p. 61-78, 1996.

. Competição: estratégias competitivas essenciais. Rio de Janeiro: Campus, 1999.

PRIEM, R. L.; BUTLER, J. E. Is the resource-based “view” a useful perspective for strategic management research? Academy of Management Review, v. 26, p. 22-40, 2001.

TIDD, J., BESSANT, J., PAVITT, K. Gestão da Inovação. Porto Alegre: Bookman, 2008.

WILLIAM, P., HOSKISSON, R., SHORT, J., YIU, D. Resource-Based Theory and Corporate Diversification: Accomplishments and Opportunities. Journal of Management, v. 37, n. 5, p.1335-1368, 2010.

REAd | Porto Alegre - Edição 79 - N 3 - setembro/dezembro 2014 - p. 838-856 
Diferenciação e foco para obtenção de vantagem competitiva: o caso da Beta Sistemas

ZOU, S.; FANG, E.; ZHAO, S. The effect of export marketing capabilities on export performance: an investigation of Chinese exporters. Journal of International Marketing, v. 11, n. 4, p. 32-55, 2003. 